\title{
O PROBLEMA DA OBJETIVIDADE JORNALÍSTICA: DUAS PERSPECTIVAS
}

\author{
Rafael Paes Henriques ${ }^{1}$ \\ Universidade Federal do Espírito Santo (UFES) \\ https://orcid.org/0000-0002-1812-5886
}

\begin{abstract}
RESUMO:
Como valor fundamental da atividade, a objetividade jornalística já foi investigada conceitualmente por diversos estudos acadêmicos cujos resultados, apesar de publicados em livros e revistas da área, não alteraram a maneira como consumidores de informação, jornalistas e até mesmo professores de jornalismo entendem filosoficamente a objetividade e, consequentemente, a sua aplicação nas rotinas e procedimentos da prática jornalística. Este artigo tem o objetivo de realizar a revisão bibliográfica de dois importantes trabalhos de autores brasileiros que investigaram a noção de objetividade. Vamos discutir as obras "A objetividade jornalística", de Luiz Amaral e "Jornalismo, fatos e interesses", de Wilson Gomes, inventariando as suas maneiras de compreender e também debater filosoficamente essa noção fundamental para a atividade.
\end{abstract}

PALAVRaS-ChaVE: Objetividade Jornalística; Subjetividade; Perspectivismo; Teoria do Jornalismo.

\section{THE JOURNALISTIC OBJECTIVITY PROBLEM: TWO PERSPECTIVES}

\begin{abstract}
:
As a fundamental value of the activity, journalistic objectivity has already been conceptually investigated by several academic studies whose results, although published in books and magazines in the area, did not change the way information consumers, journalists and even journalism teachers philosophically understand objectivity and, consequently, its application in the routines and procedures of journalistic practice. This article aims to carry out the bibliographic review of two important works by Brazilian authors that investigated the notion of objectivity. We will discuss Luiz Amaral's work "The Objectivity of Journalism" and Wilson Gomes's work "Journalism, Facts and Interests", inventing his ways of understanding and discussing this fundamental notion of the activity philosophically.
\end{abstract}

KEYWORDS: Journalistic Objectivity; Subjectivity; Perspectivism; Theory of Journalism.

\footnotetext{
${ }^{1}$ Doutor em Filosofia. Professor adjunto do Departamento de Comunicação Social, do Programa de Pós-Graduação em Comunicação e Territorialidades e do Programa de Pós-Graduação em Filosofia da Universidade Federal do Espírito Santo (UFES), Espírito Santo - Brasil. E-mail: rafaelpaesh@gmail.com
}

HENRIQUES, Rafael Paes. O problema da objetividade jornalística: duas perspectivas. Griot : Revista de Filosofia, Amargosa/Bahia, v.17, n.1, p.256-268, junho/2018. 


\section{Introdução}

A objetividade jornalística é um conceito fundamental para a atividade, já que serve de orientação e parâmetro não somente para a prática dos jornalistas, como também orienta os seus diversos públicos no consumo diário de notícias. Quem produz a informação tem a pretensão de estar de algum modo, e em alguma medida, revelando fatos e acontecimentos da realidade cotidiana. Por outro lado, quem consome as informações também o faz porque acredita que o produto jornalístico é o resultado de um trabalho comprometido, que condiz, pelo menos em algum grau, com a verdade dos fatos. Só que, apesar de ser uma noção-chave, não somente para a Teoria do Jornalismo, como também para a prática profissional, a objetividade jornalística ainda é um conceito pouco discutido pelos jornalistas e até mesmo pelos estudantes da área.

Como resultado desse "esquecimento", a noção de objetividade jornalística, que se encontra na essência, na origem da atividade, é entendida de um lado como sendo algo tão "óbvio" e "evidente" que não precisa de discussão, e, por outro, como um conceito cuja investigação não vale a pena, visto que "não vai dar em nada mesmo" ou "cujo consenso é impossível de se alcançar". Pois é justamente essa "obviedade" e "naturalidade" com que, distraidamente, se pode pré-compreender a objetividade no jornalismo que esse artigo quer questionar. Em vez de noção "evidente" ou de discussão desnecessária, visto que há muitas compreensões possíveis para o mesmo conceito, acreditamos que é justamente por isso que se deve olhar com mais atenção para essa ideia fundamental, que serve de norte para a prática cotidiana. Em outras palavras: "Portanto, uma teoria da notícia é uma forma sistemática de organização não apenas do debate no campo dos conceitos, mas também das decisões teóricas cotidianas no mundo da vida" (GOMES, 2009, p. 36).

Para uma boa parte dos autores do campo do jornalismo, o fato seria equivalente à objetividade nela mesma, separada e independente dos sujeitos, e a notícia seria o resultado da ação de sujeitos interessados, os jornalistas, sobre essa realidade inacessível: o fato puro. Seria como se, a cada acontecimento noticiado, houvesse primeiro um fato, cuja constituição é autônoma, independente e anterior aos próprios jornalistas, e somente depois, no processo de produção da notícia, entrasse em cena o interesse, ou seja, a interpretação jornalística dos acontecimentos, transformando esses acontecimentos em produtos veiculados em jornal, internet, rádio ou televisão.

Sendo assim, o papel do bom profissional seria realizar todos os esforços, isto é, cumprir com todos os rituais estratégicos, que podem até não ser capazes de anular, mas que ao menos teriam a qualidade de minimizar a interferência subjetiva nos acontecimentos. Na impossibilidade de se alcançar a objetividade nela mesma, o mais "correto" seria o jornalista adotar certos procedimentos para não macular o fato em si, ou seja, aquilo que realmente aconteceu, a fim de chegar bem próximo dessa realidade. Notícias bem-feitas seriam interpretações, o mais fielmente possíveis, para acontecimentos jornalisticamente interessantes. Esse é o

HENRIQUES, Rafael Paes. O problema da objetividade jornalística: duas perspectivas. Griot : Revista de Filosofia, 
entendimento de Sponholz, que reconhece que o conhecimento total e absoluto, isto é, da objetividade nela mesma, é impossível, mas:

\begin{abstract}
A aspiração pela objetividade deve ser entendida como a busca e aproximação da realidade. Neste sentido, ela não só é possível, como também necessária. $O$ conhecimento total da realidade continua sendo uma utopia, a busca deste é, no entanto, o que nos leva a ir adiante (SPONHOLZ, 2009, p. 13).
\end{abstract}

A partir dessa leitura, é possível não somente compreender a realização de produtos jornalísticos, como também avaliar a sua qualidade. É essa a compreensão de fundo do artigo de Hackett (1999), para quem: “[...] o jornalismo pode ser avaliado na base de sua adequação enquanto 'expressão teórica de relações sociais concretas" (HACKETT, 1999, p. 110). Nessa perspectiva, bastaria estabelecer critérios para medir o grau de pureza das notícias, que funcionariam como uma espécie de parâmetro capaz de mensurar a quantidade de desvio presente no resultado final do trabalho. Nesse tipo de análise, as notícias são investigadas a partir de uma régua, que determinaria a distância entre o fato em si e a cobertura jornalística, muitas vezes comparando os produtos do jornalismo com outros discursos menos expostos a interferências subjetivas, como o discurso científico, por exemplo. Também é a partir desse modo de compreender o jornalismo e a operação que ele realiza, que as acusações de manipulação da informação geralmente se fundamentam.

Como valor fundamental da atividade, a objetividade jornalística já foi investigada conceitualmente por diversos estudos acadêmicos cujos resultados, apesar de publicados em livros e revistas da área, não alteraram a maneira como consumidores de informação, jornalistas e até mesmo professores de jornalismo entendem filosoficamente a objetividade e, consequentemente, a sua aplicação nas rotinas e procedimentos da prática jornalística. Este artigo tem o objetivo de realizar a revisão bibliográfica de dois importantes trabalhos de autores brasileiros que investigaram a noção de objetividade. Vamos discutir as obras "A objetividade jornalística", de Luiz Amaral e "Jornalismo, fatos e interesses", de Wilson Gomes, inventariando as suas maneiras de compreender e também debater filosoficamente essa noção fundamental para a atividade. As duas obras representam dois modos bastante distintos de realizar a investigação sobre um dos mais elementares valores da atividade jornalística e de suas consequências para a prática cotidiana de produção da informação.

\title{
O inventário de Luiz Amaral
}

Em $A$ objetividade jornalística (1996), Luiz Amaral realiza uma condensada síntese de questões e autores referentes à objetividade e suas implicações para o jornalismo, considerando essa noção quase como um mito da atividade. De modo bastante abreviado, o autor apresenta algumas definições e compreensões filosóficas que fundam a organização da realidade na separação entre sujeito e objeto e

HENRIQUES, Rafael Paes. O problema da objetividade jornalística: duas perspectivas. Griot : Revista de Filosofia, Amargosa/Bahia, v.17, n.1, p.256-268, junho/2018. 
esclarece que, desde essa cisão original, a história da Filosofia se desenvolveu em períodos nos quais o sujeito foi considerado como sendo o solo ontológico da realidade, em contraposição à outras fases nas quais a objetividade passou a ser considerada como a gênese de toda a existência verdadeira. Desde esses horizontes, o autor 1) procura descrever as possíveis consequências que essas compreensões podem trazer para o fazer jornalístico; 2) identifica os principais fatores históricos que contribuíram para a adoção do princípio da objetividade pelo jornalismo; 3) problematiza de modo bastante breve o problema da verdade apontando os principais obstáculos da prática profissional; 4) apresenta alguns dos autores brasileiros e seus posicionamentos no que diz respeito à objetividade; além de 5) indicar que a noção de objetividade é substituída por alguns autores pela ideia do justo e equilibrado.

No primeiro capítulo, Amaral explica que a objetividade é uma espécie de virtude pretendida pelos textos jornalísticos se fazendo presente não somente como um princípio, mas também como um norteador de cada uma das etapas da prática jornalística. Desde o momento em que se pensa a pauta, passando pela maneira correta de apuração da notícia, até a forma de sua apresentação, a noção de objetividade se faz presente. No século XX, a objetividade constituiu-se como uma espécie de paixão, um ideal que se deve persistentemente perseguir.

Entretanto, Amaral pondera que, apesar do amplo reconhecimento da objetividade como um caro valor fundamental da atividade, não se pode negar toda a carga de subjetividade que cada um de nós carrega. Todos, inclusive os jornalistas, temos nossas crenças, valores, preconceitos, históricos familiares, formação escolar, enfim, nossos afetos e desafetos, de modo que a objetividade como ideal acaba sempre sendo confrontada com o seu contrário, isto é, com a subjetividade.

Sendo assim, restaria a investigação sobre a objetividade superar essa dicotomia. "A questão é saber se é possível, e em que grau, o ser humano descrever as coisas como elas realmente são. Independentemente da relação que temos com elas. É saber se, de fato, a objetividade é um caminho para a verdade e a realidade" (AMARAL, 1996, p. 18). Se tomarmos como pressuposto que o mundo efetivamente se organiza desde a separação entre sujeito e objeto, essas são, de fato, as derradeiras e decisivas questões para o jornalismo: será possível ao sujeito acesso à essa objetividade? Em que grau? É possível algum conhecimento independente de relação? Entendemos que a terceira pergunta da citação é anterior e ainda mais fundamental: será que a objetividade é o único ou mesmo o melhor caminho para a verdade e a realidade? Questão de fundo filosófico de urgência evidente e que precisa ser enfrentada como forma de guiar e orientar a prática do jornalismo, desfazendo mitos e refundando em novas bases seus princípios e procedimentos.

Na tentativa de responder de alguma forma a pergunta sobre a possibilidade de apreensão dos objetos neles mesmos, independentemente do sujeito para quem as coisas se realizam, Amaral faz uma compilação de definições de objetividade presentes em dicionário tanto de filosofia quanto gerais, além de apresentar uma brevíssima síntese de diversos horizontes ontológicos de autores como Platão, Aristóteles, Comte, Descartes, Marx, Kant, Schopenhauer, Weber, Kierkegaard,

HENRIQUES, Rafael Paes. O problema da objetividade jornalística: duas perspectivas. Griot : Revista de Filosofia, 
Husserl, Russel, Popper, Ricardo Jardim Andrade, Hilton Japiassu e até mesmo os físicos Newton e Stephen Hawkins.

De um lado, o autor classifica aqueles que entendem que o fundamento de toda realidade reside no sujeito ou sua interpretação e entendimento, de outro, identifica aqueles que compreendem que a objetividade é a única e verdadeira fonte segura de real. $\mathrm{O}$ antigo embate entre idealistas e realistas é apresentado como sendo o resultado justamente desses posicionamentos ontológicos opostos. Só que em vez de investigar filosoficamente cada uma dessas possibilidades e suas consequências para o jornalismo, ou, então, no lugar de admitir um dos dois horizontes ontológicos e pesquisar as suas implicações para as teorias e práticas jornalísticas, Luiz Amaral apresenta apenas um resumo de cada um dos entendimentos desses autores concluindo o capítulo apresentando as descobertas da física quântica como prova de que a realidade em que vivemos é mesmo o resultado de "construções mentais, ao mesmo tempo caminhos e advertências" (AMARAL, 1996, p. 24). Desse modo, a tarefa seria a de saber "como pode a mídia chegar aos fatos sem alterar-lhes a substância" (AMARAL, 1996, p. 24).

Certas escolhas do autor chamam bastante a atenção nesse primeiro capítulo. Em primeiro lugar, destacamos que, apesar de apresentar um texto pretensamente equilibrado, ou seja, uma redação que não toma parte no debate entre objetivistas e subjetivistas, ao mesmo tempo em que também não pretende superar esse dualismo metafísico, Amaral acaba por reforçar essa cisão como modo correto e verdadeiro de se compreender o fundamento ontológico da existência, na medida em que a conclusão reforça uma espécie de dialética entre esses dois polos de organização do real. Como não discute satisfatoriamente com a tradição, e apenas apresenta um breve resumo do que certos pensadores elaboraram, o trabalho de Amaral termina por desviar do problema e com isso acaba não respondendo às perguntas fundamentais colocadas por ele mesmo: 1) sobre a possibilidade de uma descrição da realidade independentemente de relação e 2) se a objetividade é mesmo a gênese da realidade.

As definições de objetividade dos dicionários apresentadas e as conceitualizações dos diversos autores não colocam em questão a própria existência de uma realidade nela mesma, autônoma e independente de qualquer que seja a relação. Isso significa que a terceira e mais profunda questão sobre "saber se, de fato, a objetividade é um caminho para a verdade e a realidade", nem ao menos é atacada. Apesar de indicar a necessidade de não se pré-compreender a objetividade como o caminho óbvio e evidente para a verdade, isto é, mesmo que tenha insinuado que o modo metafísico de entender solo ontológico fundamental precisa ser problematizado, Amaral não realiza o retorno conceitual necessário para investigar se a separação sujeito-objeto é mesmo inquestionável como fundamento de existência.

Em segundo lugar, gostaríamos de destacar que chama muita atenção o fato de que, depois de apresentar as definições clássicas de objetividade presentes nos Dicionário Básico de Filosofia, de Japiassu e Marcondes, e do Novo Dicionário Aurélio, Luiz Amaral transcreve o significado de objetividade do Moderno Dicionário

HENRIQUES, Rafael Paes. O problema da objetividade jornalística: duas perspectivas. Griot : Revista de Filosofia, Amargosa/Bahia, v.17, n.1, p.256-268, junho/2018. 
Chinês classificando-o de ideológico. Isso porque nessa acepção, a objetividade é algo relativo a uma "forma de subjetivismo capitalista que advoga atitudes de isenção ou puramente objetivas, ou exclusão de opiniões pessoais na pesquisa e na análise social" (AMARAL, 1996, p. 19). Ora, mas definir a objetividade como sendo "característica daquilo que existe independentemente do pensamento" (AMARAL, 1996, p. 18) como fazem Japiassu e Marcondes também não é operar ideologicamente? Melhor ainda: acusar a definição do dicionário chinês de ser ideológica não seria o resultado de uma crença na objetividade, uma vez que tem como pressuposto que seria plenamente possível uma definição cabal e mais verdadeira, porque seria menos subjetiva, independente de relação, isenta de crenças e valores, isto é, não-ideológica?

Aliás, começar a esclarecer a questão da objetividade pela definição dos dicionários não é uma escolha inofensiva do autor, mas demonstra justamente uma opção pelas concepções supostamente descontextualizadas, baseadas em um alegado rigor e isenção do dicionário, que, na verdade, é sempre um sintoma da cristalização em um, ou mais de um, significados hegemônicos das compreensões da realidade partilhadas pelo senso comum ou mesmo pela ciência e pela filosofia. Com isso, queremos dizer que até mesmo o conjunto de definições e significados dos dicionários não é o resultado de uma operação imparcial e imaculada, mas é fruto de um tipo de relação que já se estabeleceu e resultou em um modo supostamente isento de compreender as coisas. Também queremos apontar que, escolher começar a discutir a objetividade pelas concepções frias e assépticas do dicionário, pode ser entendido como uma forma de já, de partida, tomar a ideia de objetividade como verdadeira por princípio, como fundamento último de existência, sem de fato perguntar se "a objetividade é [mesmo] um caminho para a verdade e a realidade" (AMARAL, 1996, p. 18).

No segundo capítulo, Amaral explica que a objetividade é uma noção que começou a fazer parte das preocupações do campo do jornalismo somente a partir de meados do século XIX, tendo efetivamente se generalizado após a Primeira Guerra Mundial, já no século XX. O autor identifica os principais fatores históricos que contribuíram para a adoção do princípio da objetividade pelo jornalismo: o advento das agências de notícias; o desenvolvimento industrial; as duas grandes guerras mundiais e o advento da publicidade e das relações públicas.

No terceiro capítulo, a obra apresenta muito brevemente três concepções de verdade. A mais clássica identifica a verdade como sendo o resultado de uma adaptação, ou correspondência correta do intelecto (o juízo) ao real. Já a teoria consensual determina que a verdade é fruto do consenso "entre os indivíduos de uma determinada comunidade ou cultura quanto ao que consideram aceitável ou justificável em sua maneira de encarar o real" (AMARAL, 1996, p. 46). Por último, a teoria pragmática defende a ideia de que o mais adequado critério de verdade é sua "aplicação prática, concreta, [...] sua verificação pela experiência" (AMARAL, 1996, p. 46). É claro que cada uma dessas concepções de verdade traz enormes e inúmeras consequências diretas para a atividade jornalística. Se a verdade é uma adequação da proposição ao real, o jornalismo deve perseguir essa espécie de objetividade

HENRIQUES, Rafael Paes. O problema da objetividade jornalística: duas perspectivas. Griot : Revista de Filosofia, Amargosa/Bahia, v.17, n.1, p.256-268, junho/2018. 
pressuposta, ou seja, deve sempre procurar que seus produtos sejam o mais fielmente possível desse real autônomo, independente, consequentemente, preexistente aos relatos jornalísticos. Por outro lado, se admitirmos que a verdade é o resultado de um consenso entre uma certa comunidade, a tarefa do jornalismo seria produzir notícias que estejam de acordo com o entendimento e compreensão do mais amplo público possível, no caso do jornalismo generalista, ou mesmo para um público mais restrito, quando se tratar de um produto do jornalismo segmentado. Nesse caso, a objetividade deixa de ser a gênese ou mesmo a régua que mede a verdade de toda a realidade possível. Também podemos inferir que se, por sua vez, a verdade for igual aquilo que pode ser verificado pela experiência, um renovado compromisso com os fatos e eventos, independentemente dos sujeitos para quem esses acontecimentos se realizam, parece voltar a ganhar importância. Entretanto, em vez de fazer a discussão sobre os efeitos que cada uma das perspectivas de verdade acarreta tanto para a fundamentação como para a prática do jornalismo, Amaral apenas apresenta de modo muito sucinto esses horizontes epistemológicos, indicando alguns obstáculos no caminho para a verdade na atividade jornalística: os preconceitos; os interesses materiais; a pressa; a dificuldade de tempo e espaço e a omissão.

A grande limitação do trabalho de Amaral é não apresentar nenhuma ontologia que rompa com o dualismo metafísico representado pela separação de sujeito e objeto como princípio de realidade, o que, sem dúvida alguma, poderia ter enriquecido bastante a pesquisa e poderia resultar em uma nova e mais contemporânea maneira de entender como a realidade se organiza. Consequentemente, sem essa outra compreensão, um novo fundamento para o jornalismo e uma nova maneira de o jornalista se comportar deixam de ser tornar possíveis.

É justamente esse o movimento que entendemos dever ser realizado pela Teoria do Jornalismo: dar fundamento à atividade respondendo de modo satisfatório ao modo como o próprio mundo se organiza. Se temos como compreensão filosófica, que a fonte de todo o conhecimento confiável é a objetividade, então o jornalismo deve se fundamentar nos próprios fatos e acontecimentos, isto é, nas próprias coisas. Como consequência, a prática e os procedimentos do jornalismo devem estar norteados por formas de eliminar, ou ao menos minimizar, as possíveis interferências subjetivas do jornalista. Se, por outro lado, a própria realidade se organiza desde as interpretações de nossa subjetividade, então, desde esse outro princípio fundamental, uma nova prática se faria necessária e a preocupação com certos procedimentos deixaria de se fazer necessária dando lugar a uma outra rotina e prática profissionais.

\section{A resposta de Wilson Gomes}

A análise de Wilson Gomes, em Jornalismo, fatos e interesses (2009), procura, por outro lado, realizar o debate filosófico necessário para que se possa problematizar o conceito de fato como sendo igual a objetividade nela mesma e a consequente ideia de que a tarefa do jornalista seria justamente a de apreender fielmente essa realidade "em si", desprovido de qualquer interesse. $\mathrm{O}$ trabalho tem o intuito de investigar a

HENRIQUES, Rafael Paes. O problema da objetividade jornalística: duas perspectivas. Griot : Revista de Filosofia, Amargosa/Bahia, v.17, n.1, p.256-268, junho/2018. 
fundo a relação sujeito-objeto como forma de melhor compreender a noção de objetividade jornalística e suas consequências práticas para a atividade. A ideia de Gomes é superar a polarização existente entre as respostas convencionais para o problema do real e da fundamentação da atividade jornalística: de um lado, haveria aqueles pesquisadores que acreditam na objetividade como solo ontológico de existência e, consequentemente, como parâmetro para a atividade; e de outro, localizam-se aqueles autores que entendem que a realidade é resultado de uma perspectiva, um interesse, isto é, de uma interpretação possível, sendo que, desse modo, o jornalismo perderia de vista o critério de verdade, visto que toda a interpretação, como domínio do sujeito, poderia ser considerada legítima. $\mathrm{O}$ primeiro horizonte bebe na fonte do realismo (objetivismo) e o segundo, no idealismo (subjetivismo). Gomes admite o perspectivismo ao mesmo tempo em que localiza em uma comunidade interpretativa, ou seja, na intersubjetividade, o critério de verdade, a fonte para que se possa produzir conhecimento correto e notícias confiáveis.

No primeiro capítulo, o autor realiza uma consistente investigação a respeito do conceito de fato e sua relação com a verdade e chama de realismo ingênuo o horizonte que compreende que o fato é "uma estrutura efetiva, definitiva e acessível; e o deveria ser de tal modo que o enunciado a respeito dele deveria ser necessariamente garantido por sua efetividade, inteireza e acessibilidade" (GOMES, 2009 , p. 14). Segundo essa compreensão, os acontecimentos possuiriam uma realidade independente do sujeito para quem os fatos se realizam e essa espécie de materialidade objetiva, completa e encerrada do real, possuiria uma natureza que não somente pode, mas também deve e tem por vocação ser conhecida pelo homem. Por meio dos relatos noticiosos e suas formas particulares de produção, o jornalista teria como missão reapresentar a realidade "em si mesma", cuja existência, é claro, seria autônoma e independente da relação com os sujeitos.

O realismo ingênuo talvez seja, ainda hoje, o modo majoritário de se entender a maneira como a realidade se estrutura, constituindo-se, consequentemente, como a fonte desde a qual o senso comum cria um conjunto de expectativas sobres os produtos jornalísticos e desde onde se busca fundamentar as críticas à atividade. Prova disso é que não é incomum ver publicidades de veículos de comunicação nas quais seus produtos jornalísticos são nomeados como jornalismo-verdade, e que apelam para qualificações como jornalismo isento, imparcial e que apresenta os fatos, "da maneira como ocorreram", como se nossa relação com o mundo fosse da ordem do espelhamento de uma natureza perene, imutável e disponível. Também são bastante frequentes as acusações de que determinadas coberturas jornalísticas não são objetivas, porque não apresentaram os fatos como eles realmente aconteceram.

Entretanto, Gomes explica que toda experiência de linguagem implica em construções de sentidos, não existindo discursos neutros, ou livres de propósitos; mesmo que a intenção seja parecer não ter interesse algum, como é o caso do discurso científico. É claro que isso vale também para o discurso jornalístico, um outro modo de enunciação que tem, como estratégia, apagar as marcas de sua intencionalidade. Ao realizar escolhas, no processo de construção das notícias, os profissionais da informação realizam uma atividade interessada, que imprime significado aos fatos,

HENRIQUES, Rafael Paes. O problema da objetividade jornalística: duas perspectivas. Griot : Revista de Filosofia, Amargosa/Bahia, v.17, n.1, p.256-268, junho/2018. 
que atribui sentido aos acontecimentos. Não se pode negar que a atividade jornalística considera que existem maneiras mais ou menos "adequadas" de se traduzir tudo aquilo que acontece. Tanto é assim que os manuais de redação e procedimento se constituem como importantes fontes de referência para a prática do jornalismo contemporâneo. De maneira que, na verdade, o jornalista vê o que vê, e não outros fatos e acontecimentos, e da forma como vê, desde um interesse específico: o interesse jornalístico.

[...] o conceito de fato (aquilo que há a ser percebido) é um preconceito ontológico; a ideia de círculo hermenêutico comporta justamente a tese de que apenas o que é antecipado pela consciência (ou seja, aquilo que, de alguma forma, já se sabe) pode ser conhecido, compreendido, descoberto (GOMES, 2009, p. 22-23).

$\mathrm{Na}$ verdade, diversos autores apontaram para o interesse na tentativa de indicar que toda e qualquer relação de conhecimento é uma relação na qual o homem, enquanto sujeito cognoscente, e os fatos, acontecimentos ou objetos, enquanto conhecidos, encontram-se "previamente envolvidos, implicados e complicados um com o outro" (GOMES, 2009, p. 17). É para uma espécie de natureza de co-pertencimento entre sujeito e objeto que, epistemologicamente, a noção de interesse quer apontar. A própria etimologia da palavra, como apontou Nietzsche no final do século XIX, já indica o que se está querendo dizer com interesse como elemento desde o qual nos relacionamos com o mundo, na experiência. Em latim, inter-esse significa "ser ou estar entre, situar-se no meio de alguma coisa, participar de, ter a ver com" (GOMES, 2009, p. 19).

Sendo assim, quando vai ao real, o homem já vê aquilo que vê porque já se encontra em conexão com o mundo em que vive. $O$ antigo problema do conhecimento, a saber, o da ponte ou da cópula que procura resolver a questão de como o sujeito consegue apreender a realidade exterior, revela-se, nessa perspectiva, como um falso-problema. Até mesmo a ideia de interioridade e exterioridade precisa ser revista.

Gomes procura estabelecer a relação entre a verdade e essa outra forma de organização do real: o perspectivismo; além de indicar seus limites e esclarecer o caminho conceitual desde o qual busca adotar o perspectivismo como solo ontológico de existência, sem que com isso fique refém de um inconsistente império da interpretação subjetiva. A ideia do autor é admitir a incontornável pertinência da noção de perspectivismo, isto é, da interpretação como única possibilidade de acesso ao real, mas, ao mesmo tempo, não cair apressadamente no horizonte oposto, o subjetivismo, no qual qualquer interpretação se torna possível e perde-se qualquer que seja a medida para a verificação da verdade no processo de conhecimento ou dos relatos jornalísticos. É em busca de um critério público e seguro, a partir do qual se possa julgar claramente as apreensões dos sujeitos e suas interpretações dos fatos e coisas (objetos) que o segundo capítulo da obra é edificado.

HENRIQUES, Rafael Paes. O problema da objetividade jornalística: duas perspectivas. Griot : Revista de Filosofia, Amargosa/Bahia, v.17, n.1, p.256-268, junho/2018. 
O sério limite do perspectivismo consiste no fato de que, aceitas as suas premissas com relação ao problema da verdade e falsidade dos enunciados a respeito de fatos, isto é, das notícias, não há como negar a perda da dimensão crítica. Não temos mais critérios para distinguir entre interpretação e uso, entre má-fé tornada notícia e tentativa honesta de narrar os fatos, entre uma boa e uma má interpretação de eventos. Porque, evidentemente, não se trata apenas da impossibilidade de se detectar a verdade, como também, reciprocamente, de identificar a mentira como mentira (GOMES, 2009, p. 49).

É na comunidade interpretativa pensada nos moldes de Apel ou Habermas, isto é, na intersubjetividade, que Gomes localiza um novo critério de verdade como forma de fugir do arbítrio de um sujeito que tudo pode, visto que seria a medida de todas as coisas. $O$ curioso é que no percurso argumentativo para negar o voluntarismo do sujeito e para voltar a enxergar com clareza e distinção o que é falso ou verdadeiro na realidade, Gomes acaba optando por, de algum modo, voltar a concepção realista, que ele mesmo, anteriormente, havia classificado de ingênua, visto que passa a defender a existência de um sentido próprio do fato e de uma realidade em si mesma.

O que seria, portanto, uma notícia verdadeira? Aquela sobre a qual deve ser possível um acordo universal realizado por uma comunidade ilimitada da comunicação. Dito de outra forma: aquela que de algum modo alcança o sentido próprio de um fato, portanto conformando-se nos limites dos percursos interpretativos dogmaticamente instituídos por uma comunidade de sentido (GOMES, 2009, p. 64) [grifos nossos].

Em seu modo mais extremo, o realismo ingênuo entende que seria possível ao sujeito cognoscente acessar o real nele mesmo. Em um entendimento mais moderado, o real nele mesmo pode até ser inacessível, mas sua realidade é inquestionável constituindo-se ao mesmo tempo como uma espécie de limite e de horizonte, verdadeira utopia do conhecimento que se pretenda válido. Essa última compreensão parece ser a de Gomes, na qual o jornalista pode até não ser capaz de acessar os acontecimentos neles mesmos, mas vai se esforçar para chegar o mais próximo possível desse fundamento primeiro da verdade: a objetividade cuja régua para a determinação de sua precisão é uma comunidade comunicativa.

Ao defender a ideia de um sentido próprio dos fatos, a construção teóricofilosófica de Gomes parece não compreender adequadamente a ideia de interesse. Quando ontologicamente se aponta para a inevitabilidade do interesse em qualquer que seja a relação entre sujeito e objeto, não se está querendo afirmar que toda a produção discursiva é interesseira, no sentido de que o indivíduo sempre pode interpretar os fatos ao seu modo, de acordo com o seu desejo ou arbítrio. $\mathrm{O}$ interesse não é um elemento perturbador, algo que se realizaria após a percepção para "sujar", de intencionalidade subjetiva, o que os sentidos haviam absorvido em sua natureza casta e primeira. Logo, o interesse jornalístico não é anexado ao olhar do jornalista $a$ posteriori, depois da experiência, mas constitui a sua própria condição de possibilidade. Isso quer dizer que negar a objetividade e afirmar o interesse como

HENRIQUES, Rafael Paes. O problema da objetividade jornalística: duas perspectivas. Griot : Revista de Filosofia, Amargosa/Bahia, v.17, n.1, p.256-268, junho/2018. 
solo ontológico de existência não é de modo algum afirmar o arbítrio do sujeito, ou localizar na vontade do homem o parâmetro para a definição da verdade. Em última instância, não é o sujeito que possui uma interpretação ou interesse da realidade, mas é o interesse que tem o homem; perspectiva desde a qual e a partir da qual até mesmo o homem vem a ser o que é, como é, não se constituindo como uma substância anterior a experiência.

\section{Considerações finais}

Consideramos o trabalho de Gomes mais consistente que o de Amaral, já que realiza o retorno necessário para que se possa tematizar com propriedade a ideia de objetividade jornalística. Sua mais importante contribuição é trazer a noção de perspectivismo como forma de superar o realismo ingênuo.

Entretanto, acreditamos que a pesquisa em Teoria do Jornalismo não pode tomar como óbvia e evidente a compreensão ontológica que divide a realidade em dois polos opostos: a objetividade e a subjetividade. Isso quer dizer que, antes de mais nada, discutir a noção de objetividade jornalística é investigar o modo como ontologicamente a realidade se estrutura. É desde a pergunta pela gênese do real, pelo solo de existência, que se deve começar qualquer que seja a pesquisa sobre esse que é um dos conceitos mais fundamentais, já que orienta não somente a produção, como também a própria recepção dos discursos jornalísticos pelos consumidores de informação.

Nesse sentido, é preciso romper definitivamente com a ideia de que o real pode ser compreendido desde a cisão sujeito e objeto como gênese de toda a realidade possível. Como também parte dessa separação metafísica e é desde ela que Gomes edifica toda a sua argumentação, o trabalho não consegue superar esse erro inicial e termina confundindo a negação da objetividade como sendo uma perigosa afirmação da subjetividade e, em última instância, acaba defendendo uma perspectiva ontológica carregada de uma certa nostalgia da objetividade como fonte certa e segura de verdade. Mas como já expomos anteriormente, entendemos que essa análise é fruto de uma má-compreensão do que venha a ser interesse, perspectiva, como solo ontológico de existência.

Entendemos que tanto os fatos (objeto), quanto os próprios jornalistas (sujeito) são forjados em uma relação específica; são o resultado de uma perspectiva que define não somente um modo "mais correto" de compreensão e de relato da realidade, como também determina o que é ser, pensar e agir como jornalista. Esse horizonte de análise parte da compreensão de que sujeito e objeto não são préexistentes à relação, mas são termos cuja constituição é resultado de uma mesma origem instauradora: a perspectiva. Não se trata de negar as ideias de sujeito e objeto, mas sim de reconhecer que elas são apenas derivadas, são tardias e não primárias e imediatas. Isso só se faz possível quando se pergunta pela efetiva gênese desses dois termos da relação, pela sua verdade ontológica.

O que seria originário e arcaico são as interpretações possíveis, ou seja, ontologicamente, em vez de haver acontecimento como objeto em si mesmo, e

HENRIQUES, Rafael Paes. O problema da objetividade jornalística: duas perspectivas. Griot : Revista de Filosofia, 
jornalista como sujeito anterior a qualquer que seja a experiência, há uma perspectiva que torna os dois termos da relação possíveis de se realizar. Com efeito, é sempre desde interesse jornalístico que jornalista vem a ser um sujeito que acredita que tudo aquilo que é trágico tem mais valor, e que acidente de trânsito vem a ser notícia jornalística, na forma como diariamente vem a ser, para dar apenas um exemplo. No jornalismo, o fato, que costuma ser compreendido como equivalente a objetividade nela mesma, e a perspectiva, que costuma ser entendida como um elemento posterior que é acrescentado pela subjetividade do jornalista, são, na verdade, ontologicamente uma mesma realidade que se dá num único e mesmo ato. $\mathrm{Na}$ perspectiva jornalismo, tanto os acontecimentos quanto os jornalistas se mostram e se realizam de uma certa, e não de outra, maneira. Os dois termos só são desde essa perspectiva inaugural.

HENRIQUES, Rafael Paes. O problema da objetividade jornalística: duas perspectivas. Griot : Revista de Filosofia, Amargosa/Bahia, v.17, n.1, p.256-268, junho/2018. 


\section{Referências bibliográficas}

AMARAL, Luiz. A objetividade jornalística. Porto Alegre: Sagra-Luzzatto, 1996. GOMES, Wilson. Jornalismo, fatos e interesses: ensaios de teoria do jornalismo. Florianópolis: Insular, 2009.

HACKETT, Robert. Declínio de um paradigma? A parcialidade e a objectividade nos estudos dos media noticiosos. In: TRAQUINA, Nelson. (Org.). Jornalismo: questões, teorias e "estórias". 2a. ed. Lisboa: Vega, 1999, p. 101-130.

SPONHOLZ, Liriam. Jornalismo, conhecimento e objetividade: além do espelho e das construções. Florianópolis: Insular, 2009.

TUCHMAN, Gaye. A objectividade como ritual estratégico: uma análise das noções de objectividade dos jornalistas. In: TRAQUINA, Nelson. (Org.). Jornalismo: questões, teorias e "estórias". 2a. ed. Lisboa: Vega, 1999, p. 74-90.

Autor(a) para correspondência: Rafael Paes Henriques, Universidade Federal do Espírito Santo, Av. Fernando Ferrari, 514, Goiabeiras, CEP 29075-910, Vitória - ES , Brasil. rafaelpaesh@gmail.com 